\title{
Experimental Investigation of Thermosyphon Thermal Performance Using Different Filling Ratio
}

\author{
Talib Z. Farge ${ }^{a}$, Samar J. Ismael (iD ${ }^{b}$, Rawad M.Thyab ${ }^{\mathrm{c} *}$ \\ a Electromechanical Engineering Dept., University of Technology, Iraq. 50270@uotechnology.edu.iq \\ ${ }^{\mathrm{b}}$ Electromechanical Engineering Dept., University of Technology, Iraq. 50240@uotechnology.edu.iq \\ ${ }^{c}$ Electromechanical Engineering Dept., University of Technology, Iraq. 51842@student.uotechnology.edu.iq \\ *Corresponding author.
}

Submitted: 14/03/2020

Accepted: 22/06/2020

Published: 25/01/2021

K E Y W O R D S

Thermosyphon, Thermal resistance, Thermal performance, Filling ratio, Heat dissipation.

\begin{abstract}
A B S T R A C T
The present work investigated the thermal performance of thermosyphon by using distilled water as a working fluid at different filling ratios $(50 \%$, $60 \%$, and $70 \%$ ). The thermosyphon was manufactured from a copper tube with outer and inner diameters (26 and 24) $\mathrm{mm}$, respectively. The thermosyphon was tested experimentally at different input power (100, 200 and 300) Watt. The operating temperature of the oil was chosen below $85^{\circ} \mathrm{C}$. Experimental results revealed that the filling ratio of $60 \%$ exhibited the best heat dissipation at the highest operating temperature. While the low operating temperature and $50 \%$ filling ratio show better heat dissipation. Further, it was found that the thermal resistance of the thermosyphon was obviously decreased with increasing the input power. The percentage decrease in the thermal resistance of the thermosyphon at a filling ratio of 0.6 was $14.6 \%$ compared with that filling ratio of 0.5 at an input power of $300 \mathrm{~W}$.
\end{abstract}

How to cite this article: T. Z. Farge, S. J. Ismael, R. M. Thyab, "Experimental investigation of thermosyphon thermal performance using different filling ratio" Engineering and Technology Journal, Vol. 39, Part A, No. 01, pp. 34-44, 2021.

DOI: https://doi.org/10.30684/etj.v39i1A.1639

This is an open access article under the CC BY 4.0 license http://creativecommons.org/licenses/by/4.0

\section{INTRODUCTION}

It is well known that the thermosyphon is widely used in various engineering disciplines. [1,2]. Much attention has been paid to examine power savings and environmental issues. Accordingly, the thermosyphon has been developed and implemented for the use of renewable energy sources, heat recuperation of small-grade heat energy and refrigeration equipment. The solar heating of building [3], extraction of geothermal energy for power generation [4,5], solar thermal appliances [6], cooling application turbine blade and transformer [7,8] are the best examples. Thermosyphons are composed 
of two parts, the first part called a condenser section and the evaporator section is the second part, at the time with the adiabatic section between the condenser section and evaporator section. The heat is received by the thermosyphon evaporator section from the heat sink is transferred to the working fluid which evaporator at very low pressure. This vapor moves upward, due to the pressure difference between the two sections with the assistance of the buoyancy force towards the condenser section. Then, the vapor would be rejected the latent heat through the condenser section to the surroundings, which condenses to liquid and returns to the evaporator section by gravity for another cycle. Bala et al. [9], made a numerical analysis as well as experimental work, in order to characterize the influence of different parameters on the thermosyphon performance. Limin Maa et al. [10], investigated the thermal performance of the thermosyphon by using different working fluids such as (R134a, R601, R245fa, R600a, R1234ze, R152a, R245fa/R152a and R601/R245fa). The thermosyphon was made from a copper pipe with a $40 \mathrm{~mm}$ diameter and $3 \mathrm{~m}$ length. The obtained results revealed that the working fluid R245fa / R152a exhibits the best heat dissipation than the other working fluids. Rafal Andrzejczyk [11], studied the influences of different parameters on the performance of the wickless heat pipe by using input power ranged from $300 \mathrm{~W}$ to $50 \mathrm{~W}$. Also, was used cooling water to cool the condenser section at constant inlet temperature and constant mass flow rate with different working fluids (water, ethanol, and SES36(1,1,1,3,3-Pentafluorobutane)) and various filling ratios $(0.32,0.51$, 1.0). It was found that the thermosyphon thermal resistance decreased with an increase the input power and it was increased with increasing in the filling ratio. Abreu and Colle [12], investigated the thermal performance of uncommon geometry thermosyphon with a straight evaporator and a semicircle condenser. It was examined different lengths of the evaporator, working fluids, cooling temperatures, filling ratios, evaporator slops and heat input powers. The experimental results showed that the thermal resistance decreased with an increase in the cooling temperature at the lowest fill ratio. The findings obtained in this study can be used in the design and construction of a compact solar domestic hot water system (SDHWS) prototype. Jafari et al. [13], studied the performance of the thermosyphon numerically and experimentally to optimize the best value of filling ratio for the thermosyphon at different operation conditions. It was used the input heat in the range between $700 \mathrm{~W}$ and $30 \mathrm{~W}$, by filling ratios $16 \%$ and $135 \%$. It was found that the best performance of the thermosyphon at filling ratio below $35 \%$ for water as working fluid. Also, the experimental results showed a good agreement with that made by a mathematical model. Heris et al. [14], studied the performance of the thermosyphon by adding an oxidized carbon nanofluid to the distilled water as a working fluid. Various filling ratios and different input powers were examined. A reasonable comparison was made between the thermosyphon performance with and without using nanofluid. It was found that the thermosyphon performance improved significantly by using a working fluid with adding nanofluid. Farge et al. [15], examined the impact of various diameters of thermosyphon and working fluid on the thermosyphon efficiency. The obtained results showed that the thermosyphon thermal performance improved by increasing the tube diameterof the thermosyphon. Alammar et al. [16], observed the impact of geyser boiling on the thermal performance of TPCT at different fill ratios of the water which was used as working fluid $(25 \%, 65 \%, 100 \%)$. Various tilt angles with a wide range of input power were also examined. It was found that the thermosyphon thermal performance enhanced, particularly at a filling ratio of $100 \%$ and tilt angles of 30 and 90 , in spite of the increasing input power. From above, the main objective of the present work is to investigate the heat dissipation rate from the electric transformer oil to enhance the cooling rate of the oil and also to investigate the thermosyphon thermal resistance, using thermosyphons with different filling ratios and at different input powers.

\section{Calculation Procedures}

The experimental test of the thermal performance for the thermosyphon heat pipes was performed. The heat dissipation from oil by thermosyphon was calculated as follows , [17]:

Where m: mass of the oil, $(\mathrm{kg})$.

$$
\mathrm{Q}_{\text {oil }}=\dot{\mathrm{m}} \times \mathrm{Cp} \times \Delta \mathrm{T}
$$

Cp: Specific heat of the oil, $\left(\mathrm{W} / \mathrm{kg} .{ }^{\circ} \mathrm{C}\right)$.

$\Delta \mathrm{T}$ : Oil temperature difference $\left({ }^{\circ} \mathrm{C}\right)$

Also the specific heat of the oil can be calculated by usingthe equation (2) [18] : 


$$
\mathrm{Cp}=807.163+3.58 \times \text { Toil }
$$

Qoil dissipation $=$ Qoil (without thermosyphon) - Qoil (with thermosyphon) $(\mathrm{W})$

Where the thermal resistance of thermosyphon $T R$ can be obtained by using the equation (4), [19]:

$$
\mathrm{T} R=\frac{\mathrm{T} \text { e.m }-\mathrm{T} \text { c.m }}{\mathrm{Q} \text { in }} \quad\left(\frac{{ }^{\circ} \mathrm{C}}{\mathrm{W}}\right)
$$

Where: $\boldsymbol{Q} \boldsymbol{i n}$ the input power and $\boldsymbol{T} \boldsymbol{e} . \boldsymbol{m}, \boldsymbol{T} \boldsymbol{c} . \boldsymbol{m}$ Mean evaporator and condenser temperature, respectively.

\section{EXPERIMENTAL WORK}

The main parts of the test rig are consisting of the thermosyphon reservoir oil tank, electrical heater and measuring devices, as shown in Figure 1.

The thermosyphon tube was manufactured from copper material, with interior and exterior diameters (24 and 26) $\mathrm{mm}$. The length of the thermosyphon condenser and evaporator parts was designed $250 \mathrm{~mm}$ without an adiabatic part. The evaporator section was immersed in the hot oil. While the condenser section of the thermosyphon was subjected to the air to lose the heat to the atmosphere by natural free convection.

The oil reservoir (tank) was made from a galvanized sheet metal with $2 \mathrm{~mm}$ thickness, and dimensions $(400,300$ and 200) $\mathrm{mm}$. The top surface of the oil reservoir was contained three ports. The first port used to fix the electrical heater at the center of the top surface, while the other two ports at the sides of the top surface used to fix the thermosyphon. The oil reservoir was filled with 24 liters of electrical transformer oil.

An electrical heater with $270 \mathrm{~mm}$ length and 1000-Watt power capacity was also utilized to heat the oil. A dimmer switch with an accuracy of $( \pm 1 \%)$ of reading and wattmeter with an accuracy of $( \pm 0.5 \%)$ of reading used to provide various input powers $(100,200$ and 300$)$, Watt.

Seven thermocouples (type k) (chromel-alumel) with a measurement error of $\pm 0.5{ }^{\circ} \mathrm{C}$ were used to measure the temperature at different positions. Three thermocouples were installed on the top of the oil surface at three positions (near the heater (T1), the middle distance between the heater and thermosyphon (T2) and on the surface of thermosyphon evaporator T3)). While, it was put three other thermocouples at the surface of the thermosyphon condenser at (the bottom (T4), middle (T5), and top (T6)). The last thermocouple was used to measure the ambient temperature (T7), as shown in Figure 2. The experimental procedures were started by cleaning the thermosyphon from inside with acetone many times. Then, the thermosyphon was evacuated to $-760 \mathrm{mmHg}$ (gauge pressure) by using a vacuum pump followed by filling the thermosyphon with working fluid at a certain value of filling ratio. The input power was chosen (100, 200 and 300) Watt to heat the oil. All the measured temperatures by thermocouples were taken by 12 channel data loggers (BTM-4208SD data logger temperature recorder). It should be noted that all the experimental tests were carried out from the ambient temperature to operate the temperature below $85^{\circ} \mathrm{C}$. 


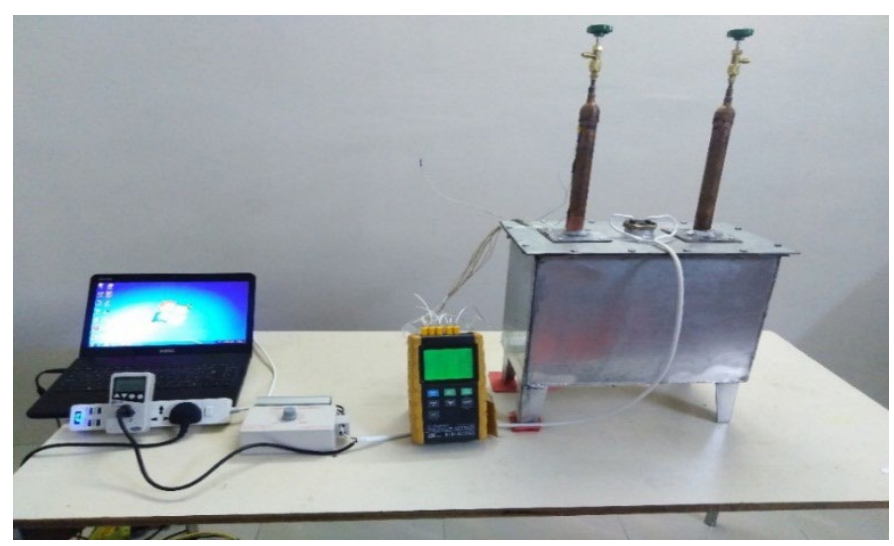

Figure 1: Thermosyphon test rig

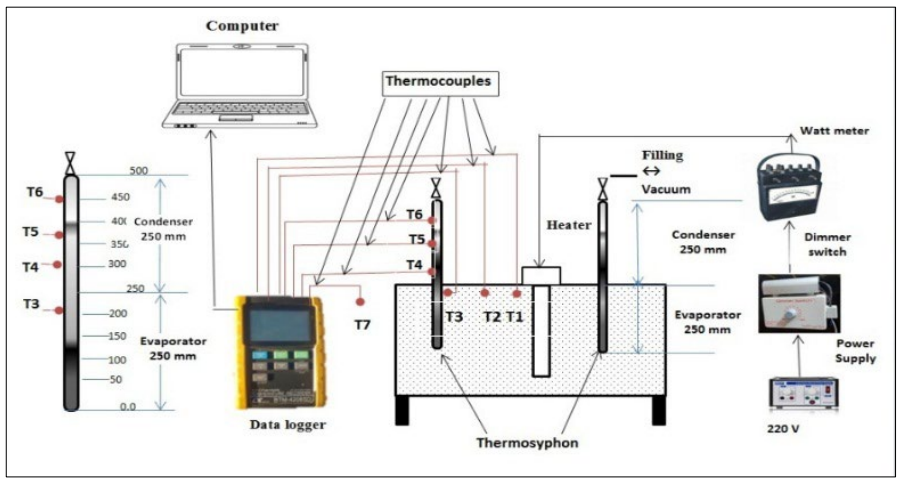

Figure 2: Sketch of thermocouples location on the thermosyphon test rig

\section{UNCERTAINTY ANALYSIS}

The uncertainty of the thermosyphon thermal resistance can be calculated from readings of the temperature along the thermosyphon and the input power.

$$
\frac{U_{R}}{R}=\sqrt{\left(\frac{u_{\Delta T e-c}}{\Delta T e-c}\right)^{2}+\left(\frac{u_{q i n}}{Q_{\text {in }}}\right)^{2}} \quad[20]
$$

Where:

$$
\mathrm{u}_{\Delta \mathrm{Te}-\mathrm{c}}=\sqrt{\left(\mathrm{u}_{\Delta \mathrm{Te}-\mathrm{av}}\right)^{2}+\left(\mathrm{u}_{\mathrm{Tc}-\mathrm{av}}\right)^{2}}
$$

The value of uncertainty is normally associated with $\Delta \mathrm{Te}-\mathrm{c}$

$\mathrm{u}_{\mathrm{Qin}}$ The value of uncertainty associated with the reading of the power Qin Also the:

Where:

$$
\Delta T_{e-c}=T_{e-a v}-T_{c-a v}
$$

$$
\mathrm{Te}-\mathrm{av}=\mathrm{T} 3
$$

(Average temperatures in the evaporator section).

$$
\mathrm{Tc}-\mathrm{av}=\frac{(\mathrm{T} 4+\mathrm{T} 5+\mathrm{T} 6)}{3}
$$

(Average temperatures in the condenser section) 
The results are shown in Table I

TABLE I: The uncertainty of the thermosyphon thermal resistance

\begin{tabular}{ccc}
\hline \hline $\begin{array}{c}\text { Qin } \\
(\mathbf{W})\end{array}$ & $\mathbf{R}\left(\mathbf{W} /{ }^{\circ} \mathbf{C}\right)$ & Maximum error $\cdot \frac{\boldsymbol{u}_{\boldsymbol{R}}}{\boldsymbol{R}}(\mathbf{\%})$ \\
\hline $\mathbf{1 0 0}$ & 0.239 & $\pm 2.9 \%$ \\
\hline $\mathbf{2 0 0}$ & 0.1595 & $\pm 2.01 \%$ \\
\hline $\mathbf{3 0 0}$ & 0.153666667 & $\pm 1.7 \%$ \\
\hline
\end{tabular}

By determining the overall uncertainty values associated with the resulting $\mathrm{R}$ values for the entire experimental range, approximately $2.9 \%$ were found, which is an appropriate value in engineering applications.

\section{RESULTS AND DISCUSSION}

Figures 3 to 5 show the average oil temperature (T1 and T2) distribution with respect to heating time for different filling ratios and different input power. It is clearly seen that the activity of the thermosyphon was started at the average oil temperature of $40^{\circ} \mathrm{C}$ for all cases. Then, the temperature between with and without using the thermosyphon was increased as the heating time increased. Also, the oil temperature difference was increased as the input power increased.

Figure 3 shows that the average oil temperature a longer time of filling ratio of 0.5 to reach the same level of oil temperature for the input power of 100 Watt than the other filling ratios.

Figure 4 displays the impact of different filling ratios on thermosyphon performance at an input power of 200 Watt which had the same effect, but with a small preference of filling ratio of 0.6 than others.

Figure 5 illustrates the thermosyphon performance at filling ratio 0.6 which clearly exhibits the best thermal performance of the thermosyphon. This was attributed to the higher heat dissipation observed at a filling ratio of 0.6 .

Figures 6 to 8 show the maximum heat time to reach the same level of an average oil temperature at different filling ratios and input powers. Obviously, the heat dissipation rate was directly proportional to the heating time. The highest heat dissipation rate by the thermosyphon leading to the highest heating time, which gives the best thermal performance of the thermosyphon.

Figure 6 shows the best thermal performance of thermosyphon at a filling ratio of 0.5 at an input power of 100 Watt. Figures (6 and 7) show the best thermal performance of the thermosyphon at a filling ratio of 0.6 at an input power of 200 and 300 Watt. From Figures 6 to 8, it can be recommended to use a thermosyphon with a 0.5 filling ratio in the case of low input power. While at higher input power filling ratio 0.6 can be used.Figure 9 shows the heat dissipation from the oil at different filling ratios and input powers. It was observed that the amount of heat dissipation increased with increasing input power. Also, a filling ratio of 0.5 exhibits higher rate dissipation at input power 100 Watt. While the filling ratio 0.6 shows a high rate of heat dissipation at 200 and 300 Watt

Figures 10 to12 show the temperature distribution along the thermosyphon condenser outer surface at three-position, top (T6), middle (T5) and bottom (T4) with respect to the heating time at different filling ratios and input powers. Each case of input power had the same maximum temperature.

It can be seen an obvious oscillation in the temperature values along the heating time. This oscillation was extremely reliant on the ratio and input power. The amplitude of the oscillating was increased from the top towards the bottom of the thermosyphon condenser. However, the oscillation effect was decreased as the input power increased.

In fact, the oscillation phenomenon occurred when the partial pressure increased and decreased inside the thermosyphon, due to the evaporation and condensation processes. The partial pressure was increased in the case of the working fluid evaporated, which led to an increase in the temperature inside the thermosyphon. Also, the temperature was decreased inside the thermosyphon as the partial pressure decreased, due to the condensation of the vapor. 
Figure 13 shows the temperature distribution along the thermosyphon at different input powers and filling ratios. The temperature at the evaporator section was shown higher value at higher input power. Additionally, the temperature difference between the evaporator section and the beginning of the condenser section was found higher at higher input power.

In the case of temperature distribution along the condenser section, Figure 13 shows a reduction in the temperature difference between the different input powers toward the tip of the thermosyphon and to reach approximately the same value of temperature at the thermosyphon tip especially at filling ratios of 0.5 and 0.6 . This was due to the geyser boiling and lower thermal resistance at the higher input power.

Figure 14 illustrates the relationship between the thermal resistance of the thermosyphon and filling ratio at different input powers. It can be seen that the thermal resistance of thermosyphon decreased with increasing the input power and reached the lowest value at input power 300 Wand filling ratio of 0.6. In fact, this considered to be the best thermal performance and heat dissipation of thermosyphon. The percentage decrease in the thermal resistance of the thermosyphon at a filling ratio of 0.6 was observed $14.6 \%$ compared with that filling ratio of 0.5 at an input power of $300 \mathrm{~W}$.

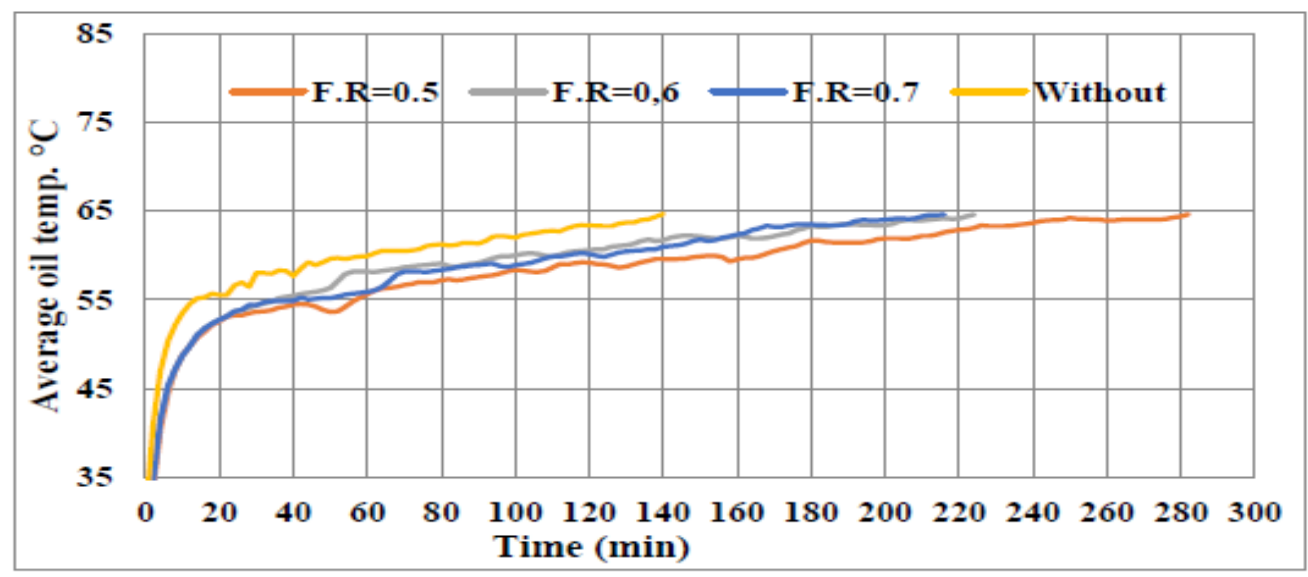

Figure 3: The average values of the oil temperature with respect to the time at different filling ratios and power supply 100 Watt

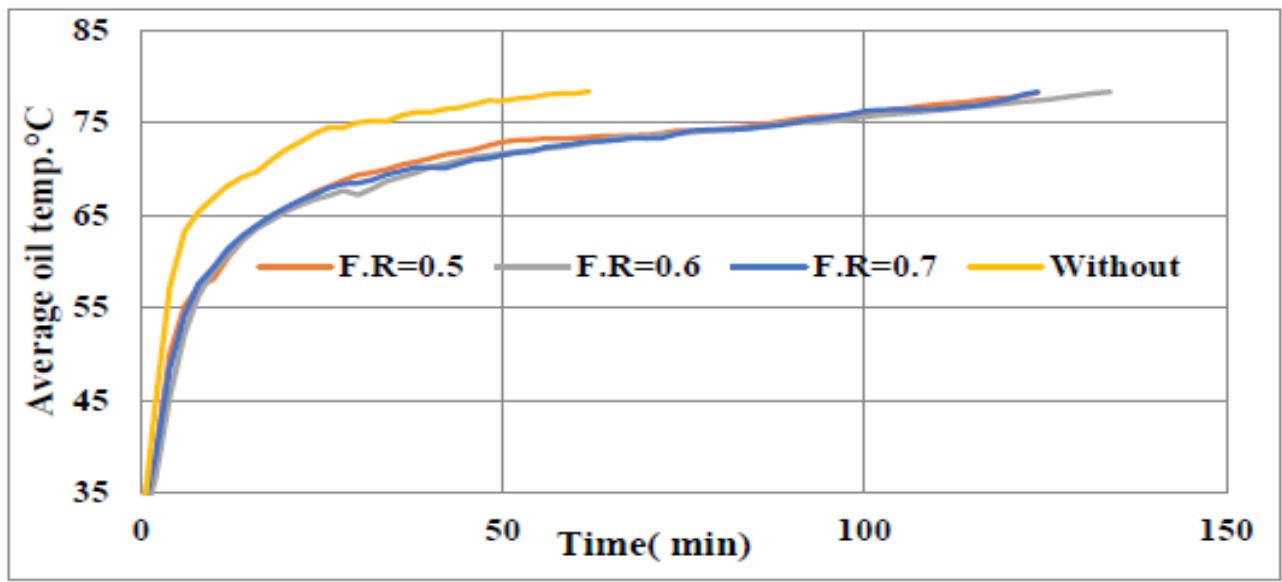

Figure 4: The average values of the oil temperature with respect to the time at different filling ratios and power supply 200 Watt 


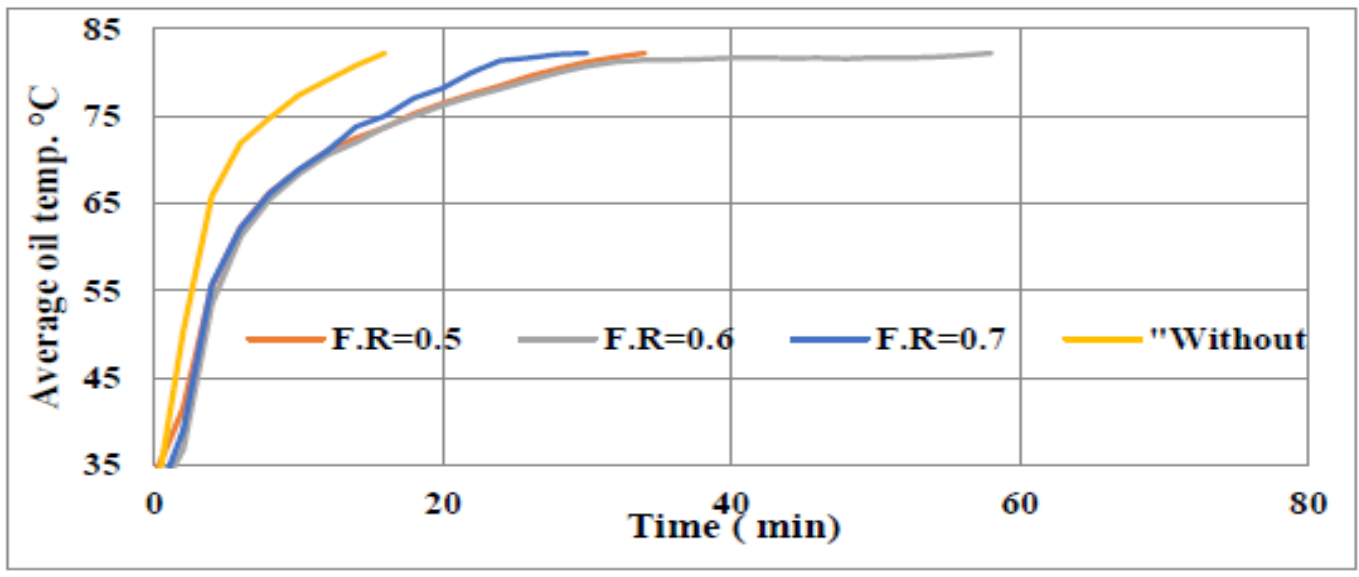

Figure 5: The average values of the oil temperature with respect to time for different filling ratios at power supply 300 Watt

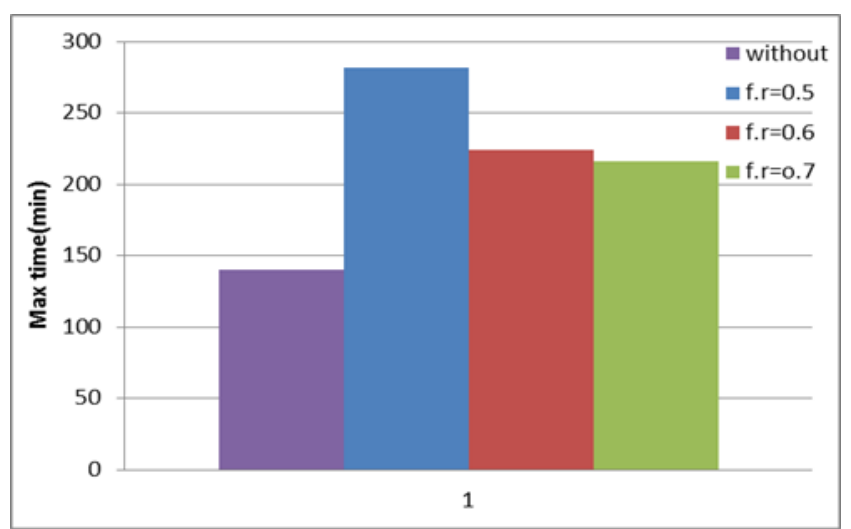

Figure 6: Relationship between maximum time and the different filling ratio at a power supply of 100W

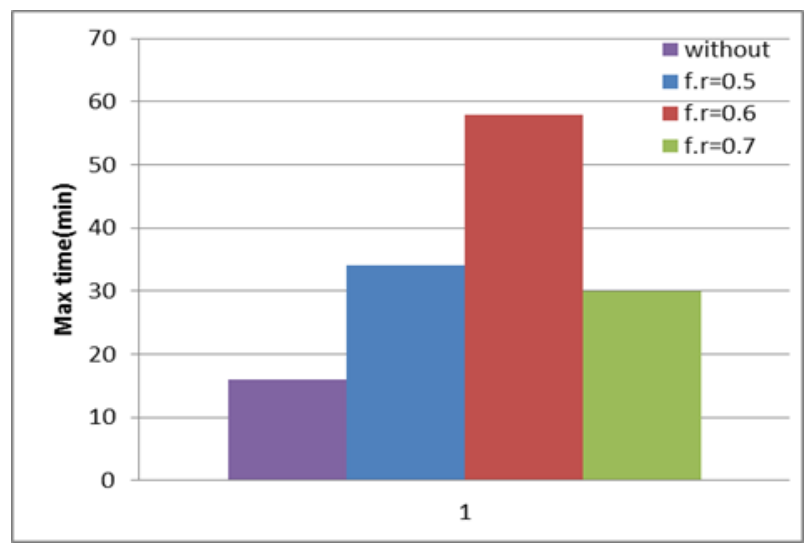

Figure 7: Relationship between maximum time and the different filling ratio at a power supply of 200W 


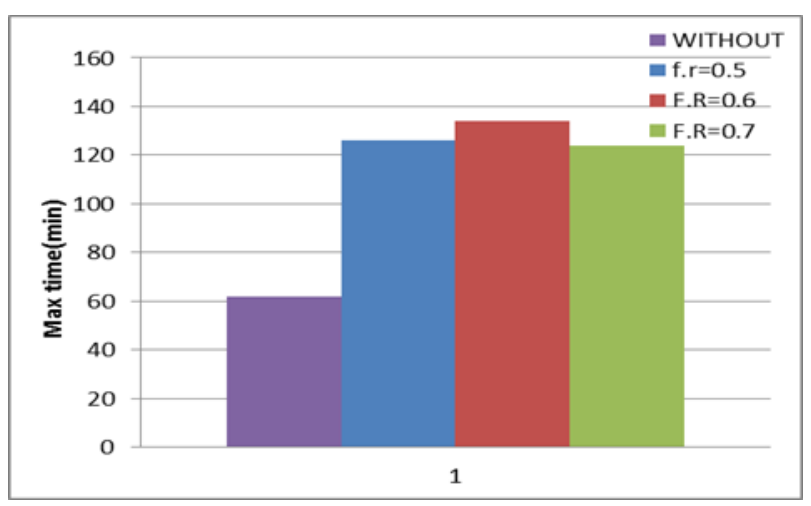

Figure 8: Relationship between the maximum time and the filling ratio at a power supply of $300 \mathrm{~W}$

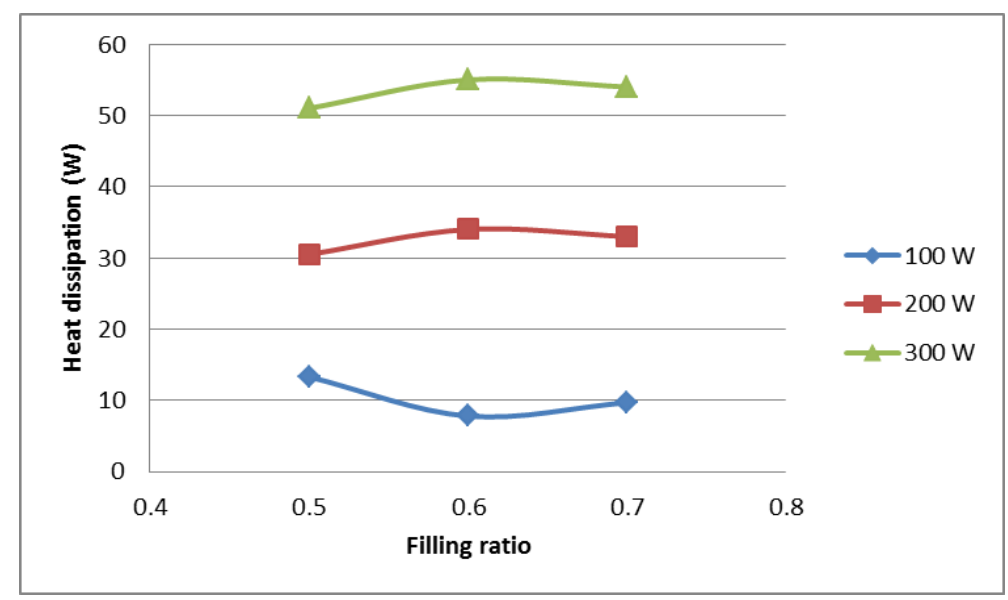

Figure 9: Heat dissipation with respect to filling ratio at the different power supply

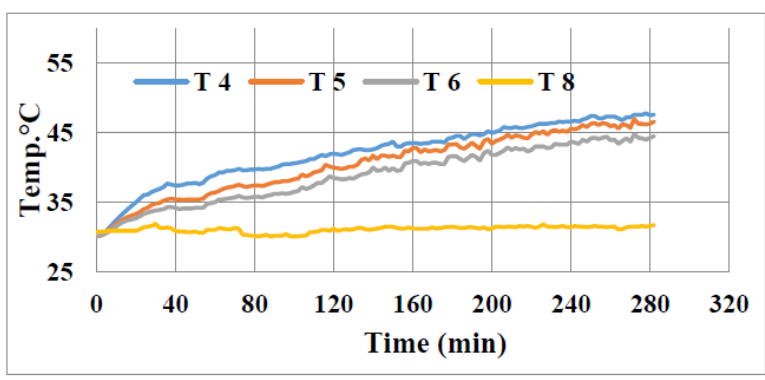

a) Filling ratio $=0.5$

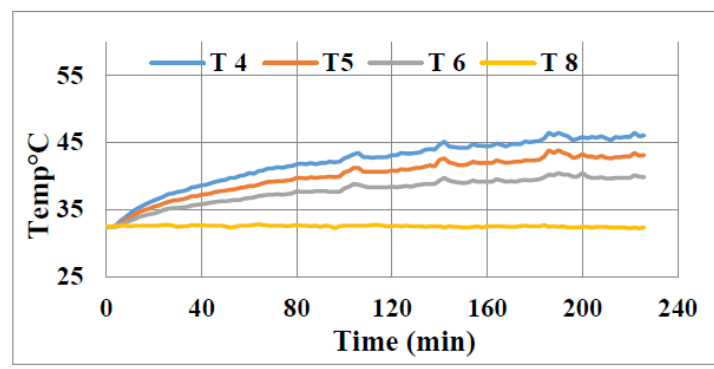

b) Filling ratio $=0.6$

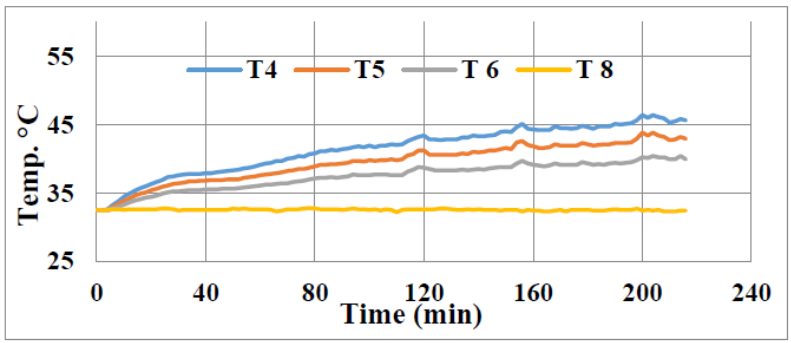

c) Filling ratio $=0.7$

Figure 10: Condenser surface temperature distribution with respect to time for load $100 \mathrm{~W}$ 


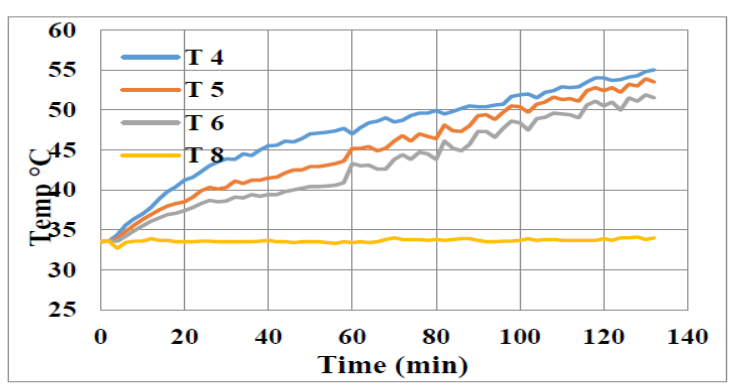

a) Filling ratio $=0.5$

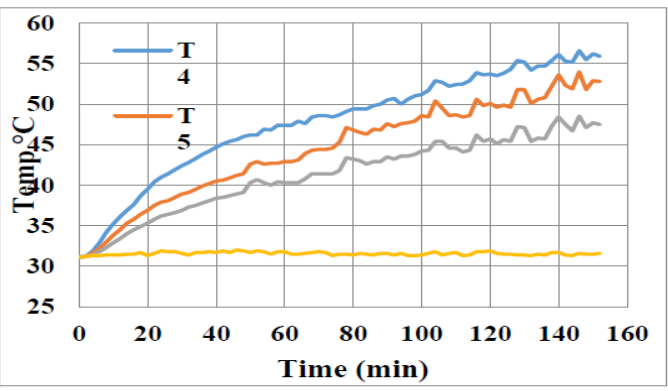

b) Filling ratio $=0.6$

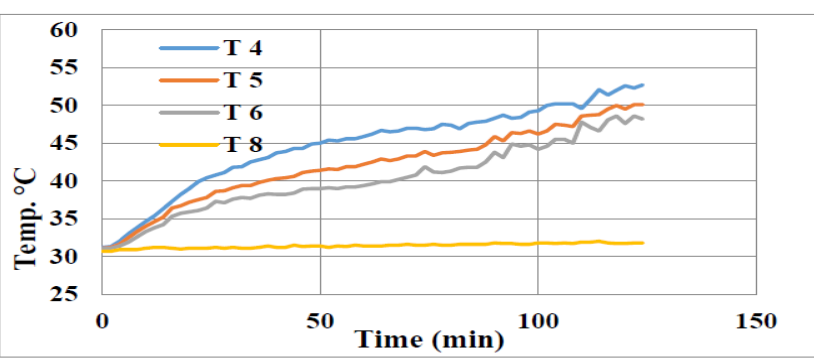

c) Filling ratio $=0.7$

Figure 11: Condenser surface temperature distribution with respect to time for load $200 \mathrm{~W}$

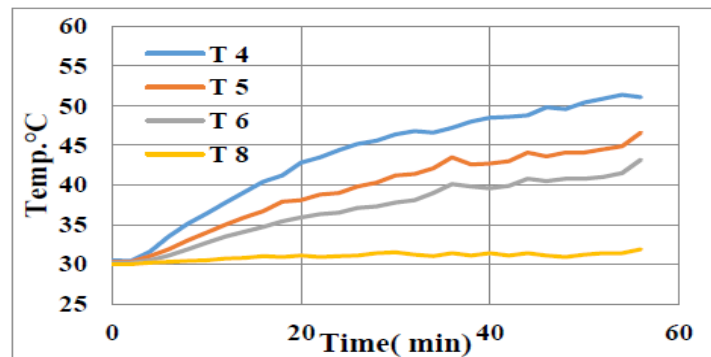

a) filling ratio $=0.5$

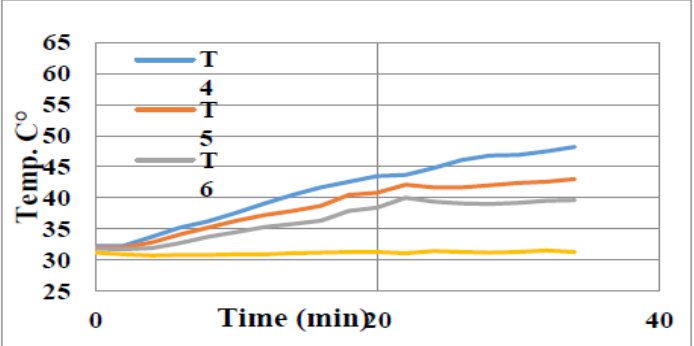

b) filling ratio $=0.6$

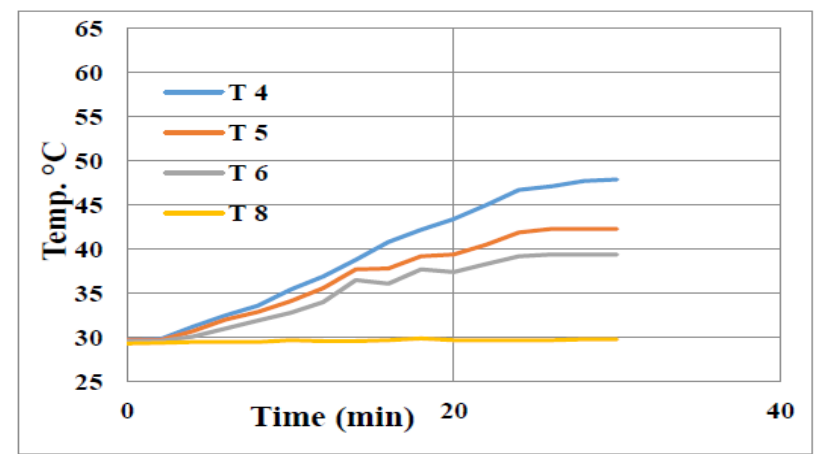

c) Filling ratio $=0.7$

Figure 12: Condenser surface temperature distribution with respect to time for load $300 \mathrm{~W}$ 


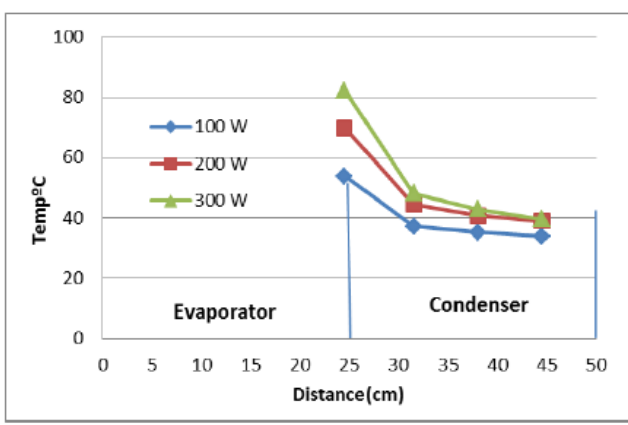

a) Filling ratio $=0.5$

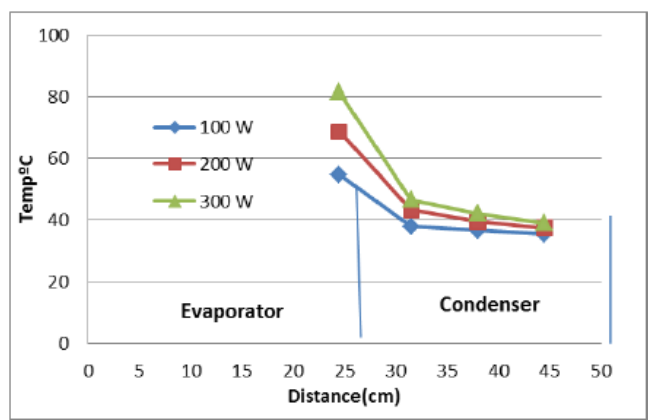

b) Filling ratio $=0.6$

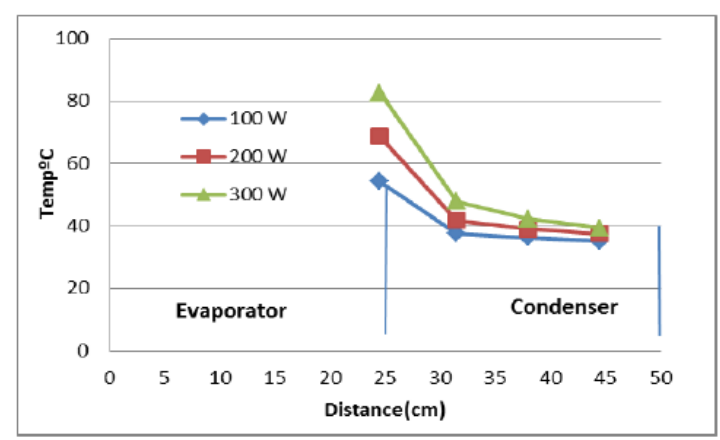

c) Filling ratio $=0.7$

Figure 13: Temperature distribution along the thermosyphon with various input power

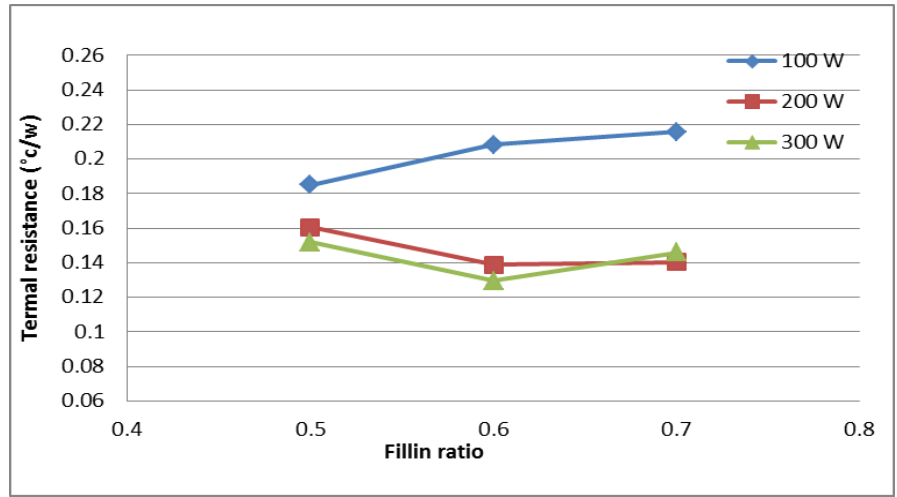

Figure 14: The relation between thermal resistance and filling ratio

\section{Conclusions}

The following results were obtained from the present research:

1) The operating activity of thermosyphon which filling with pure water as working fluid was started from the operating temperature of $40^{\circ} \mathrm{C}$ approximately at a suitable value of filling ratios.

2) The best value of thermosyphon filling ratio of the distilled water was 0.5 in the case of the low input power, while in the case of a higher power was 0.6 .

3) The rate of heat dissipation increased with increasing the input power. Also, the filling ratio 0.5 shows high performance at low input power. While filling ratio 0.6 gives high performance at high power.

4) The temperature distribution along the thermosyphon condenser exhibited oscillations in the temperature values, where the amplitude of oscillations was increased from the top toward the bottom of the thermosyphon condenser.

5) The values of the thermal resistance of the thermosyphon decreased with increasing the input powers for all filling ratios. Further, the percentage decrease in the thermosyphon thermal resistance at a filling ratio of 0.6 was observed $14.6 \%$ compared with that filling ratio of 0.5 at an input power of $300 \mathrm{~W}$. 


\section{References:}

[1] D. A. Reay, Kew. P. A, R. J. Mcglen, Heat pipes: Theory design and application, $6^{\text {th }}$ book ed.Oxford, UK: Butterworth-Heinemann, 2014.

[2] D. Jafari, A. Franco, S. Filippeschi, P. D. Marco, Two-phase closed thermosyphons: A review of studies and solar applications, Renewable and Sustainable Energy Reviews, 53(2016) 575-593. http://dx.doi.org/10.1016/j.rser.2015.09.002

[3] M. E. Pouland, A. Fung, Potential benefits from thermosiphon - PCM (TP) integrated design for buildings applications in Toronto, Proceedings of eSim 2012: The Canadian Conference on Building Simulation.

[4] A. Franco, M. Vaccaro, On the use of heat pipe principle for the exploitation of medium below temperature geothermal resources, Applied Thermal Engineering, 59(2013) 189-199. http://dx.doi.org/10.1016/j.applthermaleng.2013.05.024

[5] L. L. Vasiliev, L. P. Grakovich, M. I. Rabetsky, L. L. Vassiliev Jr., A. S. Zhuravlyov, Thermosyphons with innovative technologies, Applied Thermal Engineering, 2016.

[6] S. M. Khairnasov, A. M. Naumova, Heat pipes application to solar energy systems, Appl. Sol. Energy., 52(2016) 47- 60.

[7]D. Japikse, Advances in thermosyphon technology, Adv. Heat. Transf., 9 (1973) 1-111. https://doi.org/10.1016/S0065-2717(08)70061-3

[8] C. Rosas, N. Moraga. V. Bubnovich, R. Fischer, Improvement of the cooling process of oil-immersed electrical transformers using heat Pipes, IEEE. Trans. Power. Deliv., 20(2005). http://dx.doi.org/10.1109/TPWRD.2004.838625

[9] B. Abdullahi, R. K. Al -dadah, S. Mahmoud, Thermosyphon heat pipe technology, KUST., 2019. http://dx.doi.org/10.5772/intechopen.85410

[10] L. Ma, L. Shang, D. Zhong, Z. Ji, Experimental performance of a two-phase closed thermosyphon charged with hydrocarbons and freon refrigerants for renewable energy applications, Energy Procedia, 105(2017) 5147 - 5152. http://dx.doi.org/10.1016/j.egypro.2017.03.1044

[11] R. Andrzejczyk, Experimental investigation of the thermal performance of a wickless heat pipe operating with different fluids: water, ethanol, and ses36. analysis of influences of instability processes at working operation parameters, Energies, 12(2019) 80-233 . https://doi.org/10.3390/en12010080

[12] S. L. Abreu, S. Colle, An experimental study of two-phase closed thermosyphons for compact solar domestic hot-water systems, Sol. Energy., 76(2004). https://doi.org/10.1016/j.solener.2003.02.001

[13] D. Jafari, S. Filippeschi, A. Franco, P. D. Marco, Unsteady experimental and numerical analysis of a twophase closed thermosyphon at different filling ratios, Exp. Therm. Fluid Sci., 81(2017) 164-174. http://dx.doi.org/10.1016/j.expthermflusci.2016.10.022

[14] S. Z. Heris, M. Fallahi, M., M. Shanbedi, A. Amiri, Heat transfer performance of two-phase closed thermosyphon with oxidized CNT/water nanofluids, Heat. Mass. Transf., 52(2016) 85-93. https://doi.org/10.1007/s00231-015-1548-9

[15] T. Z. Farge, S. R. Al-Sakini, A. A. Ismael, Examining the impact of different thermosyphon edema meter and working fluid performance, Eng. Technol. J., 37(2019)46 -51. http://dx.doi.org/10.30684/etj.37.2A.2

[16] A. A. Alammar, R. K. Al-Dadah, S. M. Mahmood, Experimental Investigation of the Influence of the Geyser Boiling Phenomenon on the Thermal Performance of a Two-phase Closed Thermosyphon, J. Clean. Prod., 172(2017) 2531-2543. https://doi.org/10.1016/j.jclepro.2017.11.157

[17] H. Jouhara, A. J. Robinson, Experimental investigation of small diameter two-phase closed thermosyphons charged with water, FC-84, FC-77\&FC-3283, Appl. Therm. Eng., 30(2010) 201-211.

[18] A. R. T. Campos, I. C. Mariscal, S. G. Hernandez, Simulation of a distribution transformer, WSEAS. Trans., Issue3, 7( 2012).

[19] Nikhil E. Chaudhary, NachthaVijra, T. p. Singh "Computational fluid dynamics analysis of two -phase thermosiphon, Int. J. Eng. Technol., 5 (2013).

[20] J. R. Taylor, An Introduction to error analysis: the study of uncertainties in physical Measurements, University Science, Books, 2nd Edition, 1997. 